\section{WATER OPERATIONS TECHNICAL SUPPORT PROGRAM}

TECHNICAL REPORT W-92-3

\title{
DETERMINATION OF CHLORINATED PHENOXYACID HERBICIDES IN WATER AND SEDIMENT BY SOLID PHASE EXTRACTION AND HIGH-PERFORMANCE LIQUID CHROMATOGRAPHY
}

by

Karen F. Myers

Environmental Laboratory

DEPARTMENT OF THE ARMY

Waterways Experiment Station, Corps of Engineers 3909 Halls Ferry Road, Vicksburg, Mississippi 39180-6199

\section{US-CE-C PROPERT OF THE UNITED STATES GOVERNMENT}

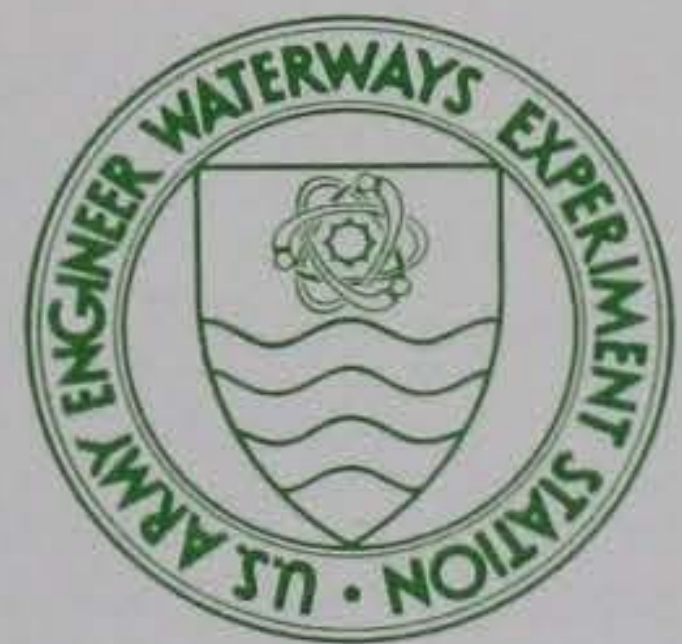

November 1992

Final Report

Approved For Public Release; Distribution Is Unlimited

RESEARCH LIBRARY US ARMY ENGINEER WATERWAYS

EXPERIMENT STATION VICKSBURG, MISSISSIPPI

Prepared for DEPARTMENT OF THE ARMY U.S. Army Corps of Engineers Washington, DC 20314-1000 
Public reporting burden for this collection of information is estimated to average 1 hour per response. inciuding the time for reviewing instructions, searching existing data sources, gathering and maintaining the data needed, and completing and reviewing the collection of information. Send comments regarding this burden estimate or any other aspect of this collection of information Davis Highway. Suite 1204, Arlington, VA 22202-4302. and to the Otfice of Management and Budget, Paperwork Reduction Project (0704-0188), Washington, DC 20503.
1. AGENCY USE ONLY (Leave blank)
2. REPORT DATE
November 199'2
3. REPORT TYPE AND DATES COVERED
Final report

4. TITLE AND SUBTITLE
Determination of Chlorinated Phenoxyacid Herbicides in Water and

Sediment by Solid Phase Extraction and High-Performance Liquid

Chromatography

6. AUTHOR(S)

Karen F. Myers

7. PERFORMING ORGANIZATION NAME(S) AND ADDRESS(ES)

U.S. Army Engineer Waterways Experiment Station

Environmental Laboratory

3909 Halls Ferry Road, Vicksburg, MS 39180-6199

8. PERFORMING ORGANIZATION REPORT NUMBER

Technical Report W-92-3

9. SPONSORING/MONITORING AGENCY NAME(S) AND ADDRESS(ES)

U.S. Army Corps of Engineers, Washington, DC 20314-1000

10. SPONSORING/MONITORING AGENCY REPORT NUMBER

11. SUPPLEMENTARY NOTES

Available from National Technical Information Service, 5285 Port Royal Road, Springfield, VA 22161.

12a. DISTRIBUTION/AVAILABILITY STATEMENT

12b. DISTRIBUTION CODE

Approved for public release; distribution is unlimited.

13. ABSTRACT (Maximum 200 words)

U.S. Environmental Protection Agency (USEPA) regulations require monitoring of chlorinated phenoxyacid herbicides such as 2,4-D, 2,4,5-T, and silvex in groundwater, drinking water, and wastes. Established analytical methods are time-consuming, can be hazardous, and often yield poor recoveries in routine laboratory use. This report describes a procedure for extraction of these compounds from sediment and water using solid phase extraction with analysis by high-performance liquid chromatography. This procedure yields reproducible results with recoveries of greater than 50 percent and method detection limits well below the criteria required by USEPA. Because of the nature of the extraction, this procedure can be used with a savings in preparation time, labor, and health risk.

14. SUBJECT TERMS

Chlorinated phenoxyacid herbicides

HPLC

Silvex

17. SECURITY CLASSIFICATION OF REPORT

UNCLASSIFIED
Solid phase extraction

2,4-D

2,4,5-T
18. SECURITY CLASSIFICATION OF THIS PAGE UNCLASSIFIED
15. NUMBER OF PAGES

21

16. PRICE CODE

20. LIMITATION OF ABSTRACT

SECURITY CLASSIFICATION OF ABSTRACT 


\section{Contents}

Preface $\ldots \ldots \ldots \ldots \ldots \ldots \ldots \ldots \ldots \ldots \ldots \ldots \ldots$ iv

1 -Introduction $\ldots \ldots \ldots \ldots \ldots \ldots \ldots \ldots \ldots \ldots \ldots \ldots$

2-Experimental Section $\ldots \ldots \ldots \ldots \ldots \ldots \ldots \ldots \ldots$

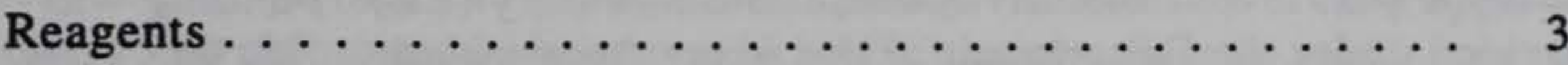

Herbicides . . . . . . . . . . . . . 3

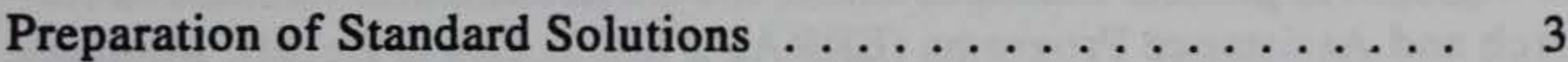

Quality Assurance Standards . . . . . . . . . . . . 4

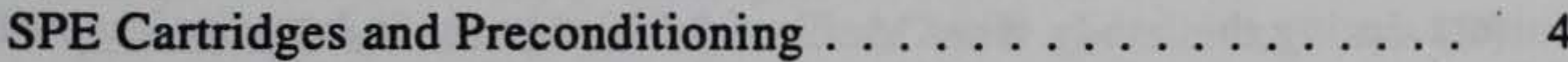

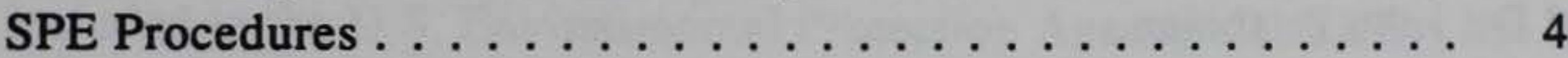

Extraction from SPE Cartridge . . . . . . . . . . 5

HPLC Apparatus and Operating Conditions $\ldots \ldots \ldots \ldots \ldots$

3-Results and Discussion $\ldots \ldots \ldots \ldots \ldots \ldots \ldots$

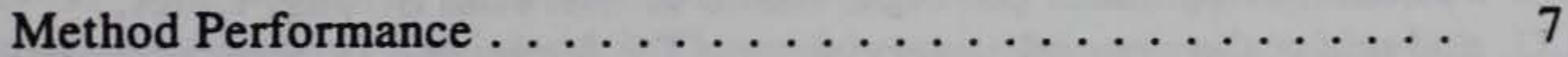

Problems Encountered . . . . . . . . . . . . 10

4-Summary $\ldots \ldots \ldots \ldots \ldots \ldots \ldots \ldots \ldots \ldots \ldots \ldots$

5-Recommendations $\ldots \ldots \ldots \ldots \ldots \ldots \ldots \ldots \ldots \ldots$

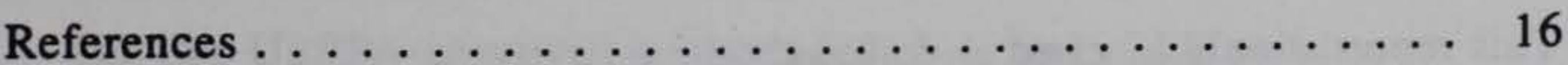

\section{List of Tables}

Table 1. Mean Recovery, Standard Deviation, and Range

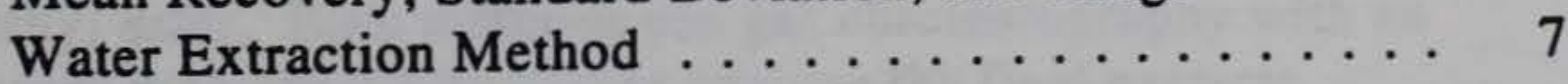

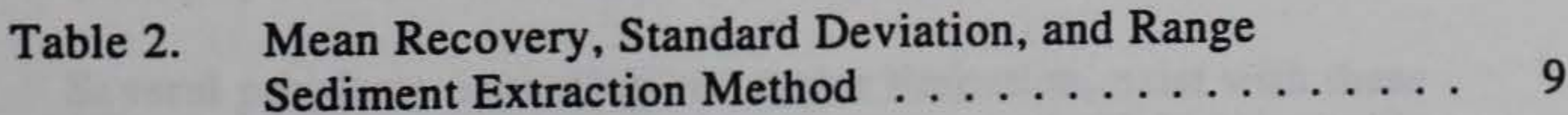

Table 3. Comparison of Method Detection Limits . . . . . . 10

Table 4. USEPA Regulatory Contaminant Levels . . . . . . . 11

Table 5. Comparison of Mean Percent Recoveries by Method ... 11 


\section{Preface}

The work reported herein was conducted as part of the Water Operations Technical Support (WOTS) Program. The WOTS Program is sponsored by the Headquarters, U.S. Army Corps of Engineers (HQUSACE), and is assigned to the U.S. Army Engineer Waterways Experiment Station (WES) under the purview of the Environmental Laboratory (EL). Funding was provided under the Department of the Army Appropriation No. 96X3123. The WOTS Program is managed under the Environmental Resources Research and Assistance Programs (ERRAP), Mr. J. Lewis Decell, Manager. Dr. A. J. Anderson was Assistant Manager, ERRAP, for WOTS. Technical Monitors during this study were Mr. Pete Juhle, Mr. James Gottesman, and Dr. John Bushman.

This study was conducted by Ms. Karen F. Myers of the Analytical Laboratory Group (ALG), Environmental Engineering Division (EED), EL. Technical assistance was received from Ms. Rita L. Anderson, EED. The work was conducted under the supervision of Ms. Ann Strong, Chief, ALG, and under the general supervision of Dr. Raymond L. Montgomery, Chief, EED, and Dr. John Harrison, Chief, EL.

At the time of publication of this report, Director of WES was Dr. Robert W. Whalin. Commander was COL Leonard G. Hassell, EN.

This report should be cited as follows:

Myers, Karen F. 1992. Determination of chlorinated phenoxyacid herbicides in water and sediment by solid phase extraction and high-performance liquid chromatography. Technical Report W-92-3. Vicksburg, MS: U.S. Army Engineer Waterways Experiment Station. 


\section{Introduction}

The use of chlorinated phenoxyacid herbicides and their derivatives has become widespread for control of broadleaf weeds in crops and for control of brush along roads and right of ways. Runoff from treated areas can adversely impact surface and groundwater quality. In addition to land applications, some chlorinated phenoxyacid herbicides are directly applied to waterways and reservoirs as aquatic herbicides for the control of weeds and algae.

Two chlorinated phenoxyacid herbicides, 2,4-D and silvex (2,4,5-TP), are included in the U.S. Environmental Protection Agency's (USEPA) list of contaminants to be monitored under the National Primary and Secondary Drinking Water Regulations (Federal Register 1989). The USEPA has proposed that states monitor vulnerable water systems for five additional herbicides from this group: Dalapon, Dicamba, 2,4-DB, Dinoseb, and 2,4,5-T. The Resource Conservation and Recovery Act Appendix IX regulations (Federal Register 1987) require groundwater monitoring of Dinoseb, silvex, 2,4-D, and 2,4,5-T around land-based hazardous waste treatment, storage, or disposal facilities. Silvex and 2,4-D are also included in the toxicity-characteristic leaching procedure (Federal Register 1990) list of contaminants.

The two USEPA-approved methods for analyzing chlorinated phenoxyacid herbicides are Method 515.1 for groundwater and drinking water (USEPA 1988) and Method 8150 for soil and water (USEPA 1987). Both methods are labor-intensive and require large volumes of organic solvent. In each method, herbicides are extracted in ethyl ether. The extract is hydrolyzed, converting ester forms of the herbicide to their corresponding free acid form. The free acid is then treated with diazomethane to form the methyl ester. Both methods use gas chromatography with an electron-capture detector (GC/ECD) to analyze the final extracts.

Several problems, including one major limitation, exist with these methods. Ethyl ether is classified as a moderate health hazard and is highly flammable. Diazomethane is carcinogenic and can be explosive under certain conditions. The spike recoveries for Method 8150 are often low because of the nature and complexity of the extraction. 
Laboratories testing for chlorinated phenoxyacid herbicides agree that new methodology is needed. Many laboratories not constrained by USEPA procedural regulations are routinely using alternate methods.

Reversed-phase high-performance liquid chromatography (RP HPLC) has become an alternative to GC/ECD as a separative analytical tool for many types of organic compounds. When sample extraction also includes a concentration step, HPLC-detection limits can be as sensitive as those achieved by GC/ECD. The USEPA has approved HPLC methods for the analysis of polynuclear aromatic hydrocarbons, Method 8310 (USEPA 1987); for the analysis of explosive residues, Method 8330 (USEPA 1990); and for the analysis of $\mathrm{N}$-methylcarbamoyloximes and $\mathrm{N}$-methylcarbamates in groundwater and finished drinking water, Method 531.1 (USEPA 1988). HPLC analysis uses solvents rather than gas as the mobile phase to elute compounds from the analytical column. The solvents most commonly used in RP HPLC are water, methanol, and acetonitrile; and the volume of solvent typically used is less than $2 \mathrm{~L} /$ day. Of the chlorinated phenoxyacid herbicides that the USEPA lists for monitoring, only Dalapon does not absorb ultraviolet (UV) light and, therefore, cannot be analyzed by HPLC. The other seven compounds are soluble in methanol and acetonitrile and chromatograph by HPLC without requiring esterification.

Solid phase extraction (SPE) is becoming increasingly popular for the concentration of trace organics from environmental water samples. SPE is easier to use, is less time-consuming, and requires smaller amounts of solvent than liquid/liquid extraction. Investigations by Hoke et al. (1986) and by Di Corcia, Marchetti, and Samperi (1989) demonstrate the potential that SPE/HPLC holds for the determination of chlorinated phenoxyacid herbicides. From the standpoint of cost and safety, a reliable method consisting of SPE extraction followed by HPLC separation and analysis would be a preferable alternative to existing USEPA methods.

This report describes an alternative for USEPA Method 8150 for both water and sediment analysis that combines and modifies existing methods for the extraction, concentration, and analysis of chlorinated phenoxyacid herbicides by SPE/HPLC. 


\section{Experimental Section}

\section{Reagents}

The following reagents were obtained from J. T. Baker: HPLC-grade methanol, acetonitrile, and trifluoroacetic acid; acetone and methylene chloride, certified for organic residue analysis; reagent-grade sodium chloride $(\mathrm{NaCl})$; and hydrochloric acid $(\mathrm{HCl})$ certified for trace metal analysis. Reagent-grade sodium hydroxide $(\mathrm{NaOH})$ was obtained from Mallinckrodt, Inc. The water was distilled reverse osmosis water prepared in the laboratory.

\section{Herbicides}

Solid chlorinated phenoxyacid herbicide standards were obtained from the Pesticides and Industrial Chemicals Repository, USEPA, Research Triangle Park, North Carolina. Compounds of interest in order of elution were: 2-methoxy-3,6-dichlorobenzoic acid (Dicamba); 2,4-dichlorophenoxyacetic acid (2,4-D); 2-(2,4-dichlorophenoxy)propionic acid (2,4-DP); 2,4,5-trichlorophenoxyacetic acid (2,4,5-T); 4-(2,4-dichlorophenoxy)butyric acid (2,4-DB); 2-(2,4,5-trichlorophenoxy)propionic acid (2,4,5-TP); and 2-(1-methylpropyl)-4,6-dinitrophenol (Dinoseb), a substituted dinitrophenol exhibiting phenoxyacid characteristics.

\section{Preparation of Standard Solutions}

Certified purities of the solid herbicide standards ranged from 97.5 to 99.9 percent. Stock standards were prepared by accurately weighing and dissolving an amount close to $0.01 \mathrm{~g}$ of dried material into acetonitrile in a $10-\mathrm{ml}$ volumetric flask. Complete dissolution of 2,4,5-T and 2,4-DB required the addition of small amounts of methanol. 
Calibration standards were prepared in acetonitrile from a multicomponent stock. After preparation, calibration standards were filtered through a 0.45- $\mu \mathrm{m}$ Millex-HV ${ }_{13}$ filter unit (Millipore Corp) in preparation for injection on the HPLC. All standards were stored at $4^{\circ} \mathrm{C}$ in amber glass bottles with Teflon-lined screw caps.

\section{Quality Assurance Standards}

Dinoseb, initially chosen as a surrogate, took 40 min to elute under the conditions of the selected HPLC method. Dicamba, a compound that elutes at $6 \mathrm{~min}$, was substituted to reduce analysis time.

The Dicamba surrogate spike was prepared at $9.4 \mathrm{ppm}$ in acetonitrile. One millilitre was added to each sample, blank and spike of both the water and the sediment matrices prior to extraction.

A stock standard for the quality assurance (QA) spiking solution containing approximately $15 \mathrm{ppm}$ of each herbicide except Dicamba was prepared in acetonitrile. The same spike was used for both matrices. One millilitre of spike was added to each sample designated as a matrix or blank spike prior to extraction.

\section{SPE Cartridges and Preconditioning}

A C18 Sep-Pak cartridge (Millipore Corp) containing $360 \mathrm{mg}$ of sorbent was used for the water extraction method. A C18 Sep-Pak Vac cartridge (Millipore Corp) containing $500 \mathrm{mg}$ of sorbent was used for the sediment extraction method. All cartridges were preconditioned prior to use as follows: cartridge sorbent beds were washed with 3 to $5 \mathrm{ml}$ of methylene chloride; rinsed with two 3- to 5-ml volumes of methanol allowing the final volume to soak the sorbent bed for $5 \mathrm{~min}$; then rinsed with $3 \mathrm{ml}$ of $0.01 \mathrm{~N} \mathrm{HCl}$ to condition the sorbent bed to the sample matrix. The cartridges were not allowed to dry out during this conditioning procedure or before the sample had completely passed through the cartridge.

\section{SPE Procedures}

An adaptation of a method described by Hoake et al. (1986) was used to extract the chlorinated phenoxyacid herbicides from river water. Five hundred millilitres of sample was filtered through a $0.7-\mu \mathrm{m}$ glass fiber filter, spiked with $1 \mathrm{ml}$ of herbicide surrogate (and $1 \mathrm{ml}$ of QA spiking solution for blank spike and matrix spike samples) and hydrolyzed with $\mathrm{NaOH}$ at pH 11 to 12 for $1 \mathrm{hr}$. The $\mathrm{pH}$ was readjusted to 2 with $\mathrm{HCl}$. One millilitre 
of methanol was added, and the sample was pumped through a preconditioned SPE cartridge. The SPE cartridge was placed in-line between $1 / 8$-in. $(0.32 \mathrm{~cm})$ Teflon tubing (emersed in the sample) and $3.90 \mathrm{cc} / \mathrm{min}$ flow-rated pump tubing (Technicon Instruments Corporation) attached to a Technicon AutoAnalyzer proportioning pump. This pump system allowed the unattended extraction of up to 20 samples in approximately $4 \mathrm{hr}$. Laboratory water blanks and blank spikes were extracted with the river water using the same method.

A modification of a method developed by USEPA Environmental Monitoring Systems Laboratory-Las Vegas (1990) was used to extract the chlorinated phenoxyacid herbicides from sediment. ${ }^{1}$ A 5- to $10-\mathrm{g}$ portion of each sample was analyzed for percent solids. Ten grams of wet sample were spiked with surrogate (and with QA spike when applicable) and extracted with $20 \mathrm{ml}$ of $0.001 \mathrm{M} \mathrm{NaOH}$ at pH 10 to 11 for $15 \mathrm{~min}$ in a sonic bath at $24^{\circ} \mathrm{C}$. The solid and liquid phases were separated by centrifugation at $2,600 \mathrm{~g}$ 's. If the $\mathrm{pH}$ of the supernate measured less than 8 , the $\mathrm{pH}$ was readjusted to 10 with $10 \mathrm{M} \mathrm{NaOH}$ and the extraction and separation steps repeated. The supernate was decanted, cleaned with $10 \mathrm{ml}$ of methylene chloride, mixed with $1 \mathrm{~g}$ of $\mathrm{NaCl}$, and recentrifuged at $2,600 \mathrm{~g}$ 's to separate the phases. Ten millilitres of the resulting supernate were transferred quantitatively to a $20-\mathrm{ml}$ vial and acidified to $\mathrm{pH} 2$ with $\mathrm{HCl}$. This extract was passed through a preconditioned SPE cartridge at a rate of $4 \mathrm{ml} / \mathrm{min}$ using a vacuum manifold system. Laboratory water blanks and blank spikes were extracted with the sediment samples using the same extraction method.

\section{Extraction from SPE Cartridge}

After sample sorption to the SPE cartridge, the sorbent bed was dried by pumping room air through the cartridge for at least $5 \mathrm{~min}$. Analytes were eluted by the addition of three $250-\mu \mathrm{L}$ volumes of acetonitrile to the cartridge sorbent bed. The acetonitrile extract was collected and brought to volume in a $1-\mathrm{ml}$ volumetric flask. The final extract was then filtered through a $0.45-\mu \mathrm{m}$ Millex-HV ${ }_{13}$ filter unit prior to injection on the HPLC.

\section{HPLC Apparatus and Operating Conditions}

The HPLC system consisted of a Waters 600-MS System Controller, a model 700 Satellite WISP Autosampler, and a model 991-MS Photodiode Array Detector with Powerline software (Waters Associates). The analytical

1 Personal Communication, June 1990, Environmental Monitoring Systems Laboratory, USEPA, Las Vegas, NV. 
column was a Waters Nova-Pak $\mathrm{C}_{18}(150 \mathrm{~mm} \times 3.9 \mathrm{~mm}$ id $)$ with a particle size of $4 \mu \mathrm{m}$. $\mathrm{AC}_{18}$ guard column preceded the analytical column. The mobile phase (adapted from the method of Di Corcia, Marchetti, and Samperi (1989)) was premixed, 45 percent water/55 percent methanol containing 0.08 percent $(\mathrm{V} / \mathrm{V})$ trifluoroacetic acid. The flow was isocratic at a rate of $0.8 \mathrm{ml} / \mathrm{min}$. The injection volume was $20 \mu \mathrm{L}$. The herbicides were monitored and peak areas integrated at $230 \mathrm{~nm}$. Sample integration utilized six multi-component calibration standards as previously described. 


\section{Results and Discussion}

\section{Method Performance}

Two sample matrices, water and sediment, were spiked with six chlorinated phenoxyacid herbicides extracted by the methods described and analyzed by RP HPLC. Both methods were found to be relatively quick and easy to use. Compared with current methodology, the volume of solvents used was significantly reduced and use of the carcinogen, diazomethane, was eliminated.

The single operator precision and accuracy for the water extraction method are shown in Table 1. The accuracy of each herbicide extracted from both the spiked laboratory water and from the spiked river water is expressed as the mean of the percent recovery for a given number of tests. The precision for each herbicide extraction is expressed as the standard deviation of the corresponding percent recoveries.

\begin{tabular}{|c|c|c|c|c|c|c|c|c|}
\hline \multirow[b]{2}{*}{ Herbicide } & \multicolumn{4}{|c|}{ Splked Lab Water } & \multicolumn{4}{|c|}{ Splked River Water } \\
\hline & Mean, \% & $s_{r}$ & Range, $\%$ & $\#$ & Mean, $\%$ & $s_{r}$ & Range,\% & $\#$ \\
\hline Dicamba & 54 & 25 & 3.6-104 & 12 & 49 & 20 & $9.2-89$ & 87 \\
\hline 2,4-D & 70 & 20 & $30-110$ & 11 & 73 & 30 & $13-134$ & 4 \\
\hline 2,4-DP & 68 & 20 & $29-108$ & 11 & 68 & 32 & 3.4-133 & 4 \\
\hline $2,4,5-\mathrm{T}$ & 63 & 20 & $24-103$ & 11 & 63 & 31 & $1-125$ & 4 \\
\hline 2,4-DB & 60 & 21 & $18-102$ & 11 & 59 & 34 & $0-127$ & 4 \\
\hline $2,4,5-T P$ & 67 & 22 & 23-111 & 11 & 63 & 30 & $2.7-123$ & 4 \\
\hline
\end{tabular}


The spiked laboratory water had a range of mean recoveries from 54 percent for Dicamba to 70 percent for 2,4-D with standard deviations ranging from 20 for 2,4-D, 2,4-DP, and 2,4,5-T to 25 for Dicamba. The spiked river water had a range of mean recoveries from 49 percent for Dicamba to 73 percent for 2,4-D. Standard deviations ranged from 20 for Dicamba to 34 for 2,4-DB.

A comparison of mean percent recoveries obtained from both the spiked laboratory water and the spiked river water exhibited a similar pattern that was independent of the number of samples analyzed (Figure 1). Analysis of variance of the mean recoveries indicated no significant differences between the individual herbicides recovered from either the spiked laboratory water matrix or from the spiked river water matrix; nor was there any statistical difference between the two matrices extracted by the water extraction method.

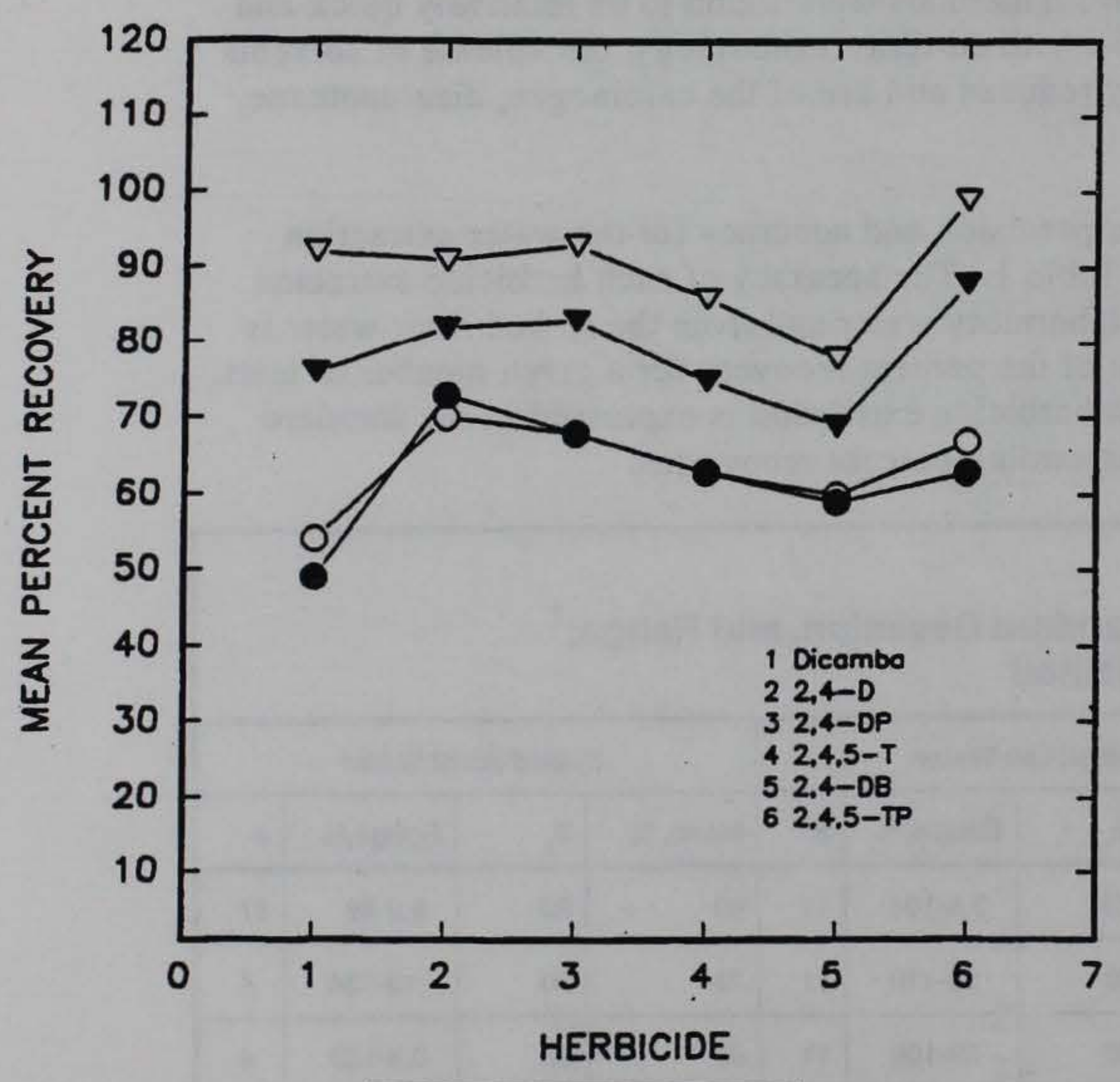

WATER EXTRACTION METHOD: O Spiked Lab Water;

SEDIMENT EXTRACTION METHOD: $\nabla$ Spiked Lab Water; $\nabla$ Spiked Sediment

Figure 1. Comparison of mean percent recoveries for the water and for the sediment extraction methods 
Table 2 presents the single operator precision and accuracy of the sediment extraction method. Data from the spiked laboratory water taken through the extraction procedure are presented along with the mean recoveries for spiked river sediment.

\section{Table 2 \\ Mean Recovery, Standard Deviation, and Range; ${ }^{1}$ Sediment Extraction Method}

\begin{tabular}{|c|c|c|c|c|c|c|c|c|}
\hline \multirow[b]{2}{*}{ Herbicide } & \multicolumn{4}{|c|}{ Splked Lab Water } & \multicolumn{4}{|c|}{ Splked River Sediment } \\
\hline & Mean, \% & $s_{r}$ & Range, \% & $\#$ & Mean, \% & $s_{r}$ & Range,\% & $\#$ \\
\hline Dicamba & 92 & 10 & $71-112$ & 8 & 76 & 19 & $38-114$ & 66 \\
\hline 2,4-D & 91 & 4.8 & 82-101 & 4 & 82 & 5.8 & $71-94$ & 8 \\
\hline 2,4-DP & 93 & 6.5 & $80-106$ & 4 & 83 & 7.7 & $67-98$ & 8 \\
\hline $2,4,5-T$ & 86 & 5.5 & $75-97$ & 4 & 75 & 9 & $57-93$ & 8 \\
\hline 2,4-DB & 78 & 8.7 & $61-96$ & 4 & 69 & 8.1 & $52-85$ & 8 \\
\hline $2,4,5-\mathrm{TP}$ & 99 & 11 & $76-121$ & 4 & 88 & 12.5 & $63-113$ & 8 \\
\hline
\end{tabular}

1 Mean = Average percent recovery; $\mathrm{Sr}=$ Standard deviation of percent recoveries; Range = Range of recovery; mean recovery \pm 2 standard deviations; \# = Number of analyses.

Spiked laboratory water mean recoveries ranged from 78 percent for 2,4-DB to 99 percent for $2,4,5$-TP. The spiked sediment mean recoveries were lower, ranging from 69 percent for 2,4 -DB to 88 percent for $2,4,5-\mathrm{TP}$ (Figure 1). Analysis of variance indicated no significant differences between individual herbicide recoveries obtained from the spiked laboratory water or between individual herbicide recoveries obtained from the spiked sediment.

Standard deviations for the sediment method using spiked laboratory water ranged from 4.8 for $2,4-\mathrm{D}$ to 11 for $2,4,5$-TP. The standard deviations for the spiked river sediment ranged from 5.8 for $2,4-\mathrm{D}$ to 19 for Dicamba. The precision, indicated by the standard deviations, was much better for the sediment extraction method than for the water extraction method. The accuracy of the analysis; indicated by the mean percent recoveries, was higher for the soil extraction method as well.

The method detection limit (MDL) was calculated from the standard deviations of 16 spiked water replicate analyses. Table 3 compares the reported MDLs of the two USEPA chlorinated phenoxyacid herbicide methods and the SPE/HPLC method. SPE/HPLC method detection limits are higher than the MDLs published for Method 515.1, with the exception of 2,4-DB; and are higher than the MDLs for Method 8150, with the exception of 2,4-D, 2,4-DP, and 2,4-DB. No SPE/HPLC data are available for Dinoseb. 


\begin{tabular}{|c|c|c|c|}
\hline \multicolumn{4}{|c|}{$\begin{array}{l}\text { Table } 3 \\
\text { Comparison of Method Detection Limits (MDL) }\end{array}$} \\
\hline Herblclde & SPE/HPLC MDL, $\mu g / L$ & Method $8150 \mathrm{MDL}, \mu \mathrm{g} / \mathrm{L}$ & Method 515.1 EDL, ${ }^{1} \mu \mathrm{g} / \mathrm{L}$ \\
\hline Dicamba & 0.36 & 0.27 & 0.081 \\
\hline 2,4-D & 0.48 & 1.2 & 0.2 \\
\hline 2,4-DP & 0.36 & 0.65 & 0.26 \\
\hline $2,4,5-T$ & 0.80 & 0.20 & 0.08 \\
\hline 2,4-DB & 0.52 & 0.91 & 0.8 \\
\hline 2,4,5-TP & 0.64 & 0.17 & 0.075 \\
\hline Dinoseb & - & 0.07 & 0.19 \\
\hline
\end{tabular}

Table 4 lists contaminant levels of the chlorinated phenoxyacid herbicides regulated by USEPA in groundwater, drinking water, and wastes along with the SPE/HPLC MDLs for these herbicides. The lower limits of detection obtainable by SPE/HPLC methods are well below current USEPA regulatory criteria. Table 5 presents a comparison of mean percent recoveries of the chlorinated phenoxyacid herbicides by method. The recoveries for Method 515.1 and Method 8150 are from the single-operator accuracy and precision data published with each method. Mean recoveries obtained from the SPE/HPLC sediment extraction method are comparable with recoveries published with the two USEPA methods while those obtained from the SPE/HPLC water extraction method are as much as 60 percent less.

\section{Problems Encountered}

Initially, for the water extraction method, a volume of $1,000 \mathrm{ml}$ was pumped through the SPE cartridge. Some of the river water samples contained too many solids even after filtering to allow $1,000 \mathrm{ml}$ to be sampled by one SPE cartridge. Often the sorbent bed became clogged on the inlet end. The volume sampled was reduced to $500 \mathrm{ml}$ and the sample filtered through a $0.7-\mu \mathrm{m}$ filter. Although the filtrate still retained some color, the amount of clogging was reduced. The compounds contributing to this color were collected on the SPE cartridge and were eluted along with the herbicides in the $1 \mathrm{ml}$ of acetonitrile. These compounds were not retained on the analytical column, but eluted as a large peak immediately after the solvent peak (Figure 2). The chlorinated phenoxyacid surrogate, Dicamba, eluted on the side of this unretained peak and was sometimes difficult to integrate. 


\begin{tabular}{|c|c|c|c|c|}
\hline Herbicide & $\begin{array}{l}\text { SPE/HPLC MDL } \\
\mu g / L\end{array}$ & $\begin{array}{l}\text { Drink|jng Water } \\
\text { MCL, }{ }_{\mu g / L}\end{array}$ & $\begin{array}{l}\text { Appendix IX } \\
\text { PQL, }{ }^{\mu} / \mathrm{L} / \mathrm{L}\end{array}$ & TCLP, $\mu g / L$ \\
\hline Dicamba & 0.36 & & & \\
\hline 2,4-D & 0.48 & 70.0 & 10.0 & 10,000 \\
\hline 2,4-DP & 0.36 & 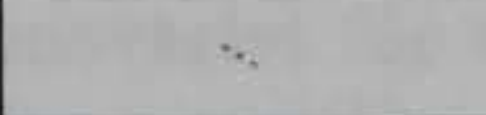 & & \\
\hline $2,4,5-T$ & 0.80 & & 2.0 & \\
\hline 2,4-DB & 0.52 & & & \\
\hline 2,4,5-TP & 0.64 & 10.0 & 2.0 & 1,000 \\
\hline Dinoseb & - & $7.0^{3}$ & 1.0 & \\
\hline \multicolumn{5}{|c|}{$\begin{array}{l}1 \mathrm{MCL}=\text { Maximum contaminant level for drinking water. } \\
2 \mathrm{PQL}=\text { Practical quantitation limit, the lowest concentration in groundwater that can be reliably } \\
\text { determined under routine laboratory operating conditions. PQL's are not part of Appendix IX } \\
\text { regulation. }\end{array}$} \\
\hline
\end{tabular}

\begin{tabular}{|c|c|c|c|c|}
\hline \multicolumn{5}{|c|}{$\begin{array}{l}\text { Table } 5 \\
\text { Comparison of Mean Percent Recoveries by Method }\end{array}$} \\
\hline Herbicide & SPE/HPLC, ${ }^{1} \%$ & SPE $/ H P L C,{ }^{2} \%$ & Method $515.1,{ }^{3} \%$ & Method $8150,{ }^{4} \%$ \\
\hline Dicamba & 54 & 92 & 135 & 79 \\
\hline 2,4-D & 70 & 91 & 131 & 75 \\
\hline 2,4-DP & 68 & 93 & 107 & 97 \\
\hline $2,4,5-T$ & 63 & 86 & 117 & 85 \\
\hline 2,4-DB & 60 & 78 & 87 & 97 \\
\hline $2,4,5-T P$ & 67 & 99 & 134 & 88 \\
\hline \multicolumn{5}{|c|}{$\begin{array}{l}1 \text { SPE/HPLC mean percent recoveries from water extraction method-laboratory water matrix. } \\
2 \text { SPEHPLC mean percent recoveries from sediment extraction method-laboratory water matrix. } \\
3 \text { Method } 515.1 \text { published average percent recoveries-reagent water matrix. } \\
4 \text { Method } 8150 \text { published single-operator mean percent recoveries-American Society for Testing } \\
\text { and Materials (ASTM) Type II water matrix. }\end{array}$} \\
\hline
\end{tabular}




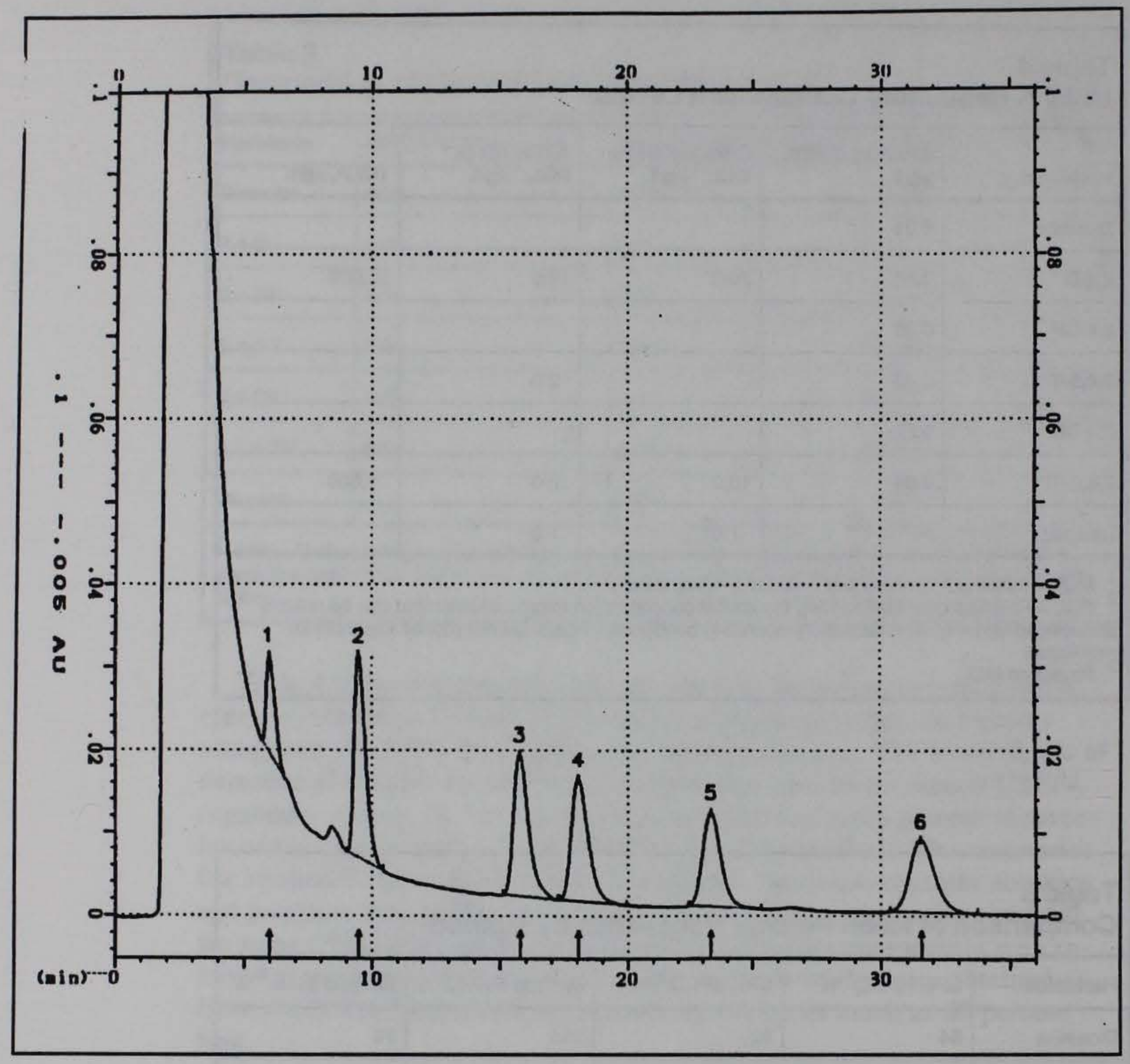

Figure 2. Chromatogram obtained from sampling $500 \mathrm{ml}$ of river water spiked with six herbicides ( $1=$ Dicamba; $2=2,4-D ; 3=2,4-D P ; 4=2,4,5-\mathrm{T} ; 5=2,4-\mathrm{DB}$; $6=2,4,5-$ TP)

The sediment extraction method required more hands-on involvement than did the water method. Disposable glassware, i.e., precleaned 40-ml volatile organic analysis (VOA) vials and disposable pipettes, was used to reduce contamination and glassware cleaning.

The texture of the river sediments ranged from fine silts with organic matter to sand. The silts required longer centrifugation to achieve separation. The VOA vials were not designed to withstand centrifugation, and some breakage ( 6 percent) occurred. After mixing with methylene chloride during the cleanup step, fine sediment particles tended to form suspensions which would not separate with centrifugation. One gram of $\mathrm{NaCl}$ 
was added to the suspension to form a thick emulsion which separated during centrifugation. $\mathrm{NaCl}$ was added to all of the samples.

As was observed with the river water samples, the sediment samples contained compounds which were not removed with the extraction and cleanup and which eluted from the analytical column immediately following the solvent peak. These compounds were present to a lesser extent in the sediment extracts than in the river water extracts.

As was previously stated, recoveries for the water extraction method appear to be lower than those for the soil extraction method. The $500-\mathrm{ml}$ water sample volume may be too large for the size SPE cartridge used, exceeding the breakthrough volumes of some of the herbicides. Different sizes of sorbent bed loadings should be tested for optimum herbicide recovery, and a cleanup step should be added either before sorption onto the SPE cartridge or before elution from the cartridge. A more centrally eluting compound might be a better choice as a surrogate.

Selection of mobile phase and flow rate was governed by the difficulty of separating 2,4-DP and 2,4,5-T. Mixtures of methanol and water and mixtures of methanol, water, and HPLC-grade acetic acid would not separate the two compounds using the HPLC equipment described. The mobile phase described by Di Corcia, Marchetti, and Samperi (1989) did separate the two compounds, but had the disadvantage of increasing the retention time of the last eluting compound, Dinoseb, to $40 \mathrm{~min}$. Dinoseb, which was not included with the compounds under investigation but was intended to be a surrogate, was eliminated from the analysis in order to reduce run time as previously stated. A gradient flow rate initiated after the 2,4-DB/2,4,5-T separation could shorten the analytical run further. In order to achieve detection limits comparable to those obtained by GC/ECD, the chlorinated phenoxyacid herbicides must be integrated at their peak maxima, $230 \mathrm{~nm}$. 


\section{Summary}

The USEPA has issued regulations that call for the monitoring of chlorinated phenoxyacid herbicides (primarily 2,4-D, silvex, and 2,4,5-T) in groundwater, drinking water, and wastes. Established analytical methods are time-consuming, can be hazardous, and often yield poor recoveries in routine laboratory use. Newly evolved technology in solid phase extraction and HPLC have made possible the development of methods to simplify and improve the analysis of these compounds. SPE is an ideal concentration step in the analysis of chlorinated phenoxyacid herbicides from water samples and lends itself to the concentration of extracts from solid samples as well.

The SPE/HPLC procedure for extraction and analysis of chlorinated phenoxyacid herbicides described in this report yields reproducible results with greater than 50-percent recovery in both water and sediment for the compounds tested. Method detection limits achieved are well below the criteria required by USEPA. Because of the nature of the extraction, the procedure can be used with a large savings in labor, preparation time, and health risk. Further optimization of the extraction will result in an even more useful and accurate procedure. 


\section{Recommendations}

Additional development should focus on maximizing extraction efficiencies and confirming the ruggedness of the procedure. Areas requiring further study include:

a. Optimization of SPE cartridge size and of sorption and elution factors.

b. Development of cleanup procedures for water samples and optimization of cleanup procedures for sediment samples.

c. Adjustment of HPLC analytical conditions to include the analysis of Dinoseb and selection of another herbicide to be used as a surrogate.

d. Development of confirmation techniques either by injection onto a second column or by use of the photodiode array detector to scan the UV spectrum of each compound. 


\section{References}

Di Corcia, Antonio, Marchetti, Marcello, and Samperi, Roberto. 1989. Extraction and isolation of phenoxy acid herbicides in environmental waters using two adsorbents in one minicartridge. Analytical Chemistry 61:1363-1367.

Federal Register. Monday, 22 May 1989. Vol 54, No. 97. National primary and secondary drinking water regulations; proposed rules.

. Thursday, 29 March 1990. Vol 55, No. 61. Hazardous waste management system; identification and listing of hazardous waste; toxicity characteristics revisions; final rule.

. Thursday, 9 July 1987 . Vol 52, No. 131. List (Phase 1) of hazardous constituents for ground-water monitoring.

Hoke, S. H., Brueggemann, E. E., Baxter, L. J., and Trybus, T. 1986.

Determination of phenoxy acid herbicides using solid-phase extraction and high-performance liquid chromatography. Journal of Chromatography 357:429-432.

U.S. Environmental Protection Agency. 1990. Test methods for evaluating solid wastes, physical/chemical methods. SW-846. Washington, DC: Office of Solid Waste and Emergency Response.

1987. Test methods for evaluating solid wastes, physical/chemical methods. SW-846, 3rd ed. Washington, DC: Office of Solid Waste and Emergency Response.

. 1988. Methods for the determination of organic compounds

in drinking water. EPA/600/4-88/039. Cincinnati, $\mathrm{OH}$ :

Environmental Monitoring Systems Laboratory. 